the fact that $30 \%$ of women of reproductive age in the USA are obese, obesity could be associated with more than $30 \%$ of the cases of pre-eclampsia. The effect of aspirin in obese women could not be assessed in the studies examined by the PARIS group because this information was often not available. These or other unrecognised subsets may be the women who benefit most from aspirin.

How should the findings of the PARIS Collaborative Group influence clinical care? The authors are appropriately circumspect with recommendations. They make the important point that, although aspirin is not apparently more effective in any high-risk subset, the number of individuals to treat for one to benefit will be lower as the percentage of women at risk increases. Deciding on the benefit:risk ratio is difficult. From the PARIS data, therapy judged by acute outcomes is safe. However, as with all therapy in pregnancy, long-range implications (unknown) must be thought about. Several years ago the UK's Royal College of Obstetrics and Gynaecology recommended, on the basis of the Cochrane meta-analysis, that it was sensible to use aspirin in pregnancies at very high risk of pre-eclampsia. ${ }^{8}$ There are certain settings in which pre-eclampsia is almost a certainty, including women with pre-eclampsia in more than one pregnancy or women with chronic hypertension and pre-eclampsia in a previous pregnancy. In these settings, aspirin is justified. In the more usual setting of risk at about $20 \%$, as in chronic hypertension, multiple gestations, prepregnancy diabetes, or preeclampsia in one previous pregnancy, whether benefits outweigh any long-term risks is more difficult to judge. Is treating 50 women to prevent one case of pre-eclampsia or one preterm birth worthwhile? Although from a public-health perspective, such a number needed to treat might seem effective, the decision is one that is probably best made individually in consultation with an informed mother.

\section{*James M Roberts, Janet M Catov}

Department of Obstetrics, Gynecology \& Reproductive Sciences (JMR) and Department of Epidemiology (JMR, JMC), University of Pittsburgh, Magee-Womens Research Institute, Pittsburgh, PA 15213, USA

rsijmr@mwri.magee.edu

JMR is mentioned as a consultant in the Askie et al paper. JMC declares that she has no conflict of interest.

1 Askie LM, Duley L, Henderson-Smart DJ, on behalf of the PARIS Collaborative Group. Antiplatelet agents for prevention of pre-eclampsia: a meta-analysis of individual patient data. Lancet 2007; published online May 17. DOI:10.1016/S0140-6736(07)60712-0.

2 Duley L, Henderson-Smart DJ, Knight M, King JF. Antiplatelet agents for preventing pre-eclampsia and its complications. Cochrane Database Syst Rev 2004; 1: CD004659.

3 Redman CW, Sacks GP, Sargent IL. Preeclampsia: an excessive maternal inflammatory response to pregnancy. Am J Obstet Gynecol 1999; 180: 499-506.

4 Gilroy DW. New insights into the anti-inflammatory actions of aspirin-induction of nitric oxide through the generation of epi-lipoxins. Memorias do Instituto Oswaldo Cruz 2005; 100 (suppl 1): 49-54

5 Vandenbroeck K, Goris A. Cytokine gene polymorphisms in multifactorial diseases: gateways to novel targets for immunotherapy? Trends Pharmacol Sci 2003; 24: 284-89.

6 Bodnar LM, Ness RB, Harger GF, Roberts JM. Inflammation and triglycerides partially mediate the effect of prepregnancy body mass index on the risk of preeclampsia. Am J Epidemiol 2005; 162: 1198-206.

7 Bodnar LM, Catov JM, Klebanoff MA, Ness RB, Roberts JM. Prepregnancy body mass index and the occurrence of severe hypertensive disorders of pregnancy. Epidemiology 2007; 18: 234-39.

8 Critchley H, MacLean A, Poston L, Walker J, eds. Pre-eclampsia, 1st edn. London: RCOG Press; 2003.

\title{
Fortification of processed cereals should be mandatory
}

See Articles page 1799 In today's Lancet, Pauline Andang'o and colleagues show that iron deficiency, the most prevalent nutrient deficiency in the world, can be reduced by addition of iron to maize flour. ${ }^{1}$ Other research has shown the success of fortification of wheat $^{2}$ and even rice ${ }^{3}$ with iron. In aggregate, these findings turn the tide: it is time to fortify the world's processed cereal foods.

The public-health importance of deficiencies of iron, iodine, and vitamin A is well accepted. Deficiencies of zinc and folic acid are increasingly recognised as problems; vitamins D and B12, calcium, selenium, and other nutrients are also claiming attention. ${ }^{4}$
Deficiencies of thiamine ${ }^{5}$ and niacin, ${ }^{6}$ linked to monotonous diets based on rice and maize, respectively, might also quietly be rising. Some populations that have, until recently, consumed traditional diets and milled their own grains within local communities are now eating increasingly available and affordable commercially processed cereals, and are therefore more vulnerable to thiamine and niacin deficiencies. For example, Brazil currently has a beriberi epidemic. Brazil's Ministry of Health has identified hundreds of people with symptoms in the past year, 37 of whom have died. ${ }^{8}$ A rice-fortification programme developed 
by PATH $^{9}$ is being used to fortify rice with thiamine in southwest Maranhão, the most affected region.

When food is voluntarily fortified by the private sector, governmental regulations generally only require that the product contains nutrients at the quantities advertised. More and more, however, companies are also required to ensure that these nutrient levels are retained after cooking. But if governments are going to mandate fortification, they need evidence that fortification is effective against nutrient deficiencies.

Iron deficiency presents special challenges. First, it is widespread, and difficult to deal with in low-income settings. Second, addition of iron to cereals can alter the colour, taste, or shelf-life of the food, and does not necessarily ensure bioavailability. ${ }^{4}$ Third, research to overcome these challenges in maize has received little attention. ${ }^{10}$ The findings of Andang'o and colleagues bring optimism because they suggest solutions for even these most serious of obstacles.

In a low-income setting in Kenya, Andang'o and colleagues fortified maize flour with sodium iron edetic acid (NaFeEDTA) and with electrolytic iron, and compared the efficacy of these fortificants on the iron status of young schoolchildren. EDTA is a chelating agent that can sequester metal ions, and electrolytic iron is the only form of elemental iron recommended for cereal fortification. 516 children, aged 3-8 years, were randomly assigned to receive the same amount of porridge five times a week. A placebo group was given porridge made from unfortified whole-maize flour; three other groups were given porridge that was fortified with either high-dose NaFeEDTA $(56 \mathrm{mg} / \mathrm{kg}$ ), low-dose NaFeEDTA $(28 \mathrm{mg} / \mathrm{kg}$ ), or electrolytic iron $(56 \mathrm{mg} / \mathrm{kg}$ ). This amount of iron would be expected to meet $18-40 \%$ of iron needs.

In intention-to-treat analyses, compared with placebo, and adjusting for baseline haemoglobin concentration, plasma concentrations of ferritin, soluble transferrin receptor, C-reactive protein, and malaria antigenaemia, electrolytic iron had no effect on iron status. However, NaFeEDTA at high dose $(56 \mathrm{mg}$ iron per $\mathrm{kg}$ maize flour) improved all measured indicators of iron status (concentrations of haemoglobin, and plasma ferritin and transferrin receptor). Low-dose NaFeEDTA (28 mg iron per $\mathrm{kg}$ maize flour) reduced the prevalence of iron deficiency only (not anaemia or iron-deficiency anaemia). What makes these findings unique is that the

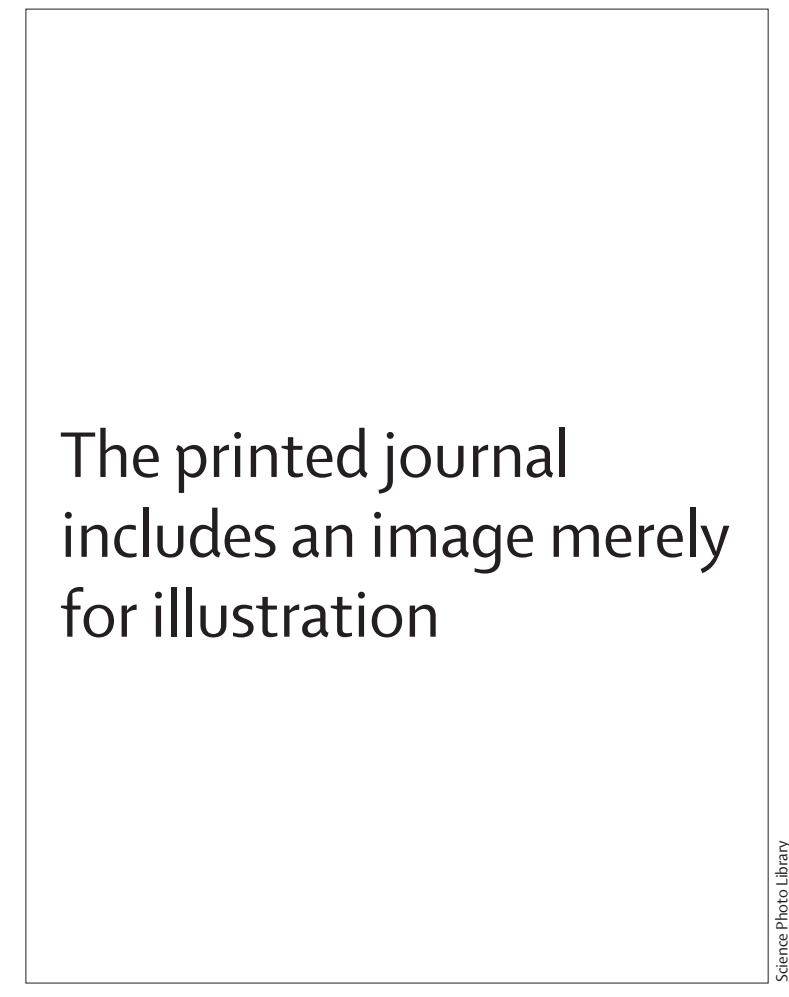

study used whole-maize flour, which is commonly eaten by poor families. The high content of phytate in such flour severely constrains iron absorption.

Methodological challenges in Andang'o and colleagues' investigation included the fact that iron deficiency was lower than expected in the study population. However, because people who are iron-deficient absorb more iron than others, this feature makes the findings more robust. As expected, in children with iron-deficiency anaemia, the effect of high-dose NaFeEDTA on haemoglobin concentration was more than three times larger than in iron-replete children. The trial ran for only 5 months. However, because the effect of additional dietary iron cumulates slowly, this short period of exposure also suggests that the intervention would be even more effective in real-life settings.

At least one of the sponsors of Andang'o and colleagues' study stands to gain from any finding that NaFeEDTA is not harmful. It should also be noted that the acceptable daily intake $(2.5 \mathrm{mg} / \mathrm{kg}$ bodyweight) was exceeded by five children participating in the study, although no adverse effects were reported. Edetic acid is widely regarded as safe, and I can find little evidence for concern about its use. However, Andang'o and 
colleagues rightly point out that continued watchfulness is called for, especially when very young children are exposed to doses above the acceptable daily intake.

Somehow, amidst the bewildering array of factors that influence and change dietary patterns, we must learn how to avoid nutritional disorders by sustainable consumption of adequate diets. In the interim, fortification offers the best available solution to the problem of nutritional deficiencies, even if such fortification is imperfect (eg, iron deficiency in young children and pregnant women can be improved but not resolved).

Fortification of centrally processed cereals will reach most vulnerable groups in countries where most people eat such foods, but will reduce the risks of overconsumption linked to fortification of some condiments. Governments that mandate fortification will, if they develop capacity for assessment and monitoring, be able to ensure that the right concentrations of the right nutrients are added to and maintained in key foods. Food fortification is one of the most sustainable and cost-effective methods available to improve public health. ${ }^{4}$

\section{Ted Greiner}

PATH, Washington DC 20006, USA

tgreiner@path.org

I direct PATH's Ultra Rice Project.

1 Andang'o PEA, Osendarp SJM, Ayah R, et al. Efficacy of iron-fortified whole maize flour on iron status of schoolchildren in Kenya: a randomised controlled trial. Lancet 2007; 369: 1799-806.

2 Zimmermann MB, Winichagoon P, Gowachirapant S, et al. Comparison of the efficacy of wheat-based snacks fortified with ferrous sulfate, electrolytic iron, or hydrogen-reduced elemental iron: randomized, double-blind, controlled trial in Thai women. Am J Clin Nutr 2005; 82: 1276-82.

3 Moretti D, Zimmermann MB, Muthayya S, et al. Extruded rice fortified with micronized ground ferric pyrophosphate reduces iron deficiency in Indian schoolchildren: a double-blind randomized controlled trial. Am J Clin Nutr 2006; 84: 822-29.

4 Allen L, de Benoist B, Dary O, Hurrell R. Guidelines on food fortification with micronutrients. Geneva, Switzerland: World Health Organization and Food and Agricultural Organisation of the United Nations, 2006.

5 Butterworth RF. Maternal thiamine deficiency: still a problem in some world communities. Am J Clin Nutr 2001; 74: 712-13.

6 Seal AJ, Creeke PI, Dibari F, et al. Low and deficient niacin status and pellagra are endemic in postwar Angola. Am J Clin Nutr 2007; 85: 218-24.

7 Juliano BO. Rice in human nutrition. 1993. http://www.fao.org/docrep/ t0567e/T0567E00.htm\#Contents (accessed May 8, 2007).

8 Maranhão Secretariat of Agriculture, Cattle, and Rural Development. Institutions join to fight beribéri in the Maranhão. March 30, 2007. http:// www.seagro.ma.gov.br/2007/4/10/Pagina350.htm (accessed May 4, 2007)

9 PATH. PATH's Ultra Rice ${ }^{\circledR}$ Project. http://www.path.org/files/MCHN ultrarice_leaflet.pdf (accessed May 3, 2007).

10 Dary O, Freire W, Kim S. Iron compounds for food fortification: guidelines for Latin America and the Caribbean 2002. Nutr Rev 2002; 60: 50-61.

\section{The performance of the Global Fund}

See Articles page 1807

In today's Lancet, Steven Radelet and Bilal Siddiqi examine the associations between evaluation scores assigned by the Global Fund to Fight AIDS, Tuberculosis and Malaria to recipient countries and characteristics of grants and countries. ${ }^{1}$ This analysis complements a previous look at the capacity of recipient countries to disburse Global Fund money. ${ }^{2,3}$ The selection of the outcome variable-grant scores $^{1}$ and disbursement rates ${ }^{2,3}$ - differed, but both analyses included several common programmatic and country-specific variables. Both studies found that poor countries are not disadvantaged compared with middle-income recipients in terms of performance. The fundamental question for both studies, however, is what does the selected outcome variable measure.

Grant performance scores from the Global Fund have several limitations. First, the recipients define the numerical targets for each quarter for the progress indicators. The scores do not allow for comparisons of progress across recipients compared with baseline. An $A$ recipient has not necessarily increased coverage of key interventions more than a B1 recipient. Category $A$ represents grants reaching or exceeding expectations, whereas B1 covers grants that have adequate performance. Second, validation of reported progress against programmatic benchmarks is inherently difficult in countries with weak health-information systems. Progress on delivery of interventions has not been assessed with population-based measurements of the delivery of the interventions funded by the grants, but rather on more upstream processes or provider-based data-collection mechanisms. Third, the evaluation process is not entirely independent and includes progress monitoring by local agents selected by the Fund.

Ultimately, assessment of both the performance of Global Fund grants and the determinants of variation in performance will have to await real data collected on the population coverage of critical interventions. The ongoing 5 -year evaluation by the Fund of its impact will provide in the next 18-24 months a detailed assessment of lessons that can be gleaned from population-level 